\title{
Teatro Down e a Performance
}

\author{
Theatre Down and Performance
}

\section{Teatro Down y Rendimiento}

\begin{abstract}
Resumo
Este artigo é um ensaio da escrita, uma reflexão da ação performática executada pelo Teatro Down, um projeto vinculado ao Núcleo de Arte, Linguagem e Subjetividade (NALS) da Universidade Federal de Pelotas - UFPel, estruturado pelos integrantes do PET-Fronteiras: Saberes e Práticas Populares. O projeto iniciou em 2013 com o objetivo de refletir a arte teatral, encontrou na ação performática seu manifesto artístico-cultural, nos permitindo acessar a diversidade no fazer. Os encontros aqui abordados buscam registrar a experiência, numa nova outra ação para concretizar e contextualizar de maneira acadêmica um turbilhão de sensações e subjetividades.
\end{abstract}

Palavras-chave: Teatro - Down - Performance - NALS.

\begin{abstract}
This article is an essay of writing, a reflection of the performative action executed by Teatro Down, a project linked with Núcleo de Artes Linguagens e Subjetividades (NALS) of the Universidade Federal de Pelotas - UFPel, organized by members of the PET- Fronteiras: Saberes e Práticas Populares. The project started in 2013 in order to reflect the theatrical art, finding in a performative way an artistic and cultural manifest, allowing us to access the diversity of doing. The meetings addressed here are seeking to record the experience, a new further action to implement and contextualize in an academic way a whirlwind of sensations and subjectiveness.
\end{abstract}

Keywords: Theatre - Down - Performance - NALS.

\section{Resumen}

Este artículo es una prueba de escritura , un reflejo de la acción performativa realizada por el Teatro de Down, un proyecto relacionado con el Centro de Arte , Lengua y Subjetividad ( NALS) de la Universidade Federal de Pelotas- UFPel. Organizado por los miembros de la PET-Fronteiras: Saberes e Práticas Populares. El proyecto se inició en 2013 con el fin de reflejar el arte teatral, que se encuentra en la acción performativa su manifiesto artístico y cultural, que nos permite acceder a la diversidad en la fabricación. Las reuniones abordaron 
aquí tratan de registrar la experiencia, una nueva acción adicional para aplicar y contextualizar forma académica un torbellino de sensaciones y subjetividades.

Palabras Claves: Teatro - Down - Rendimiento - NALS.

\section{1-Considerações Iniciais:}

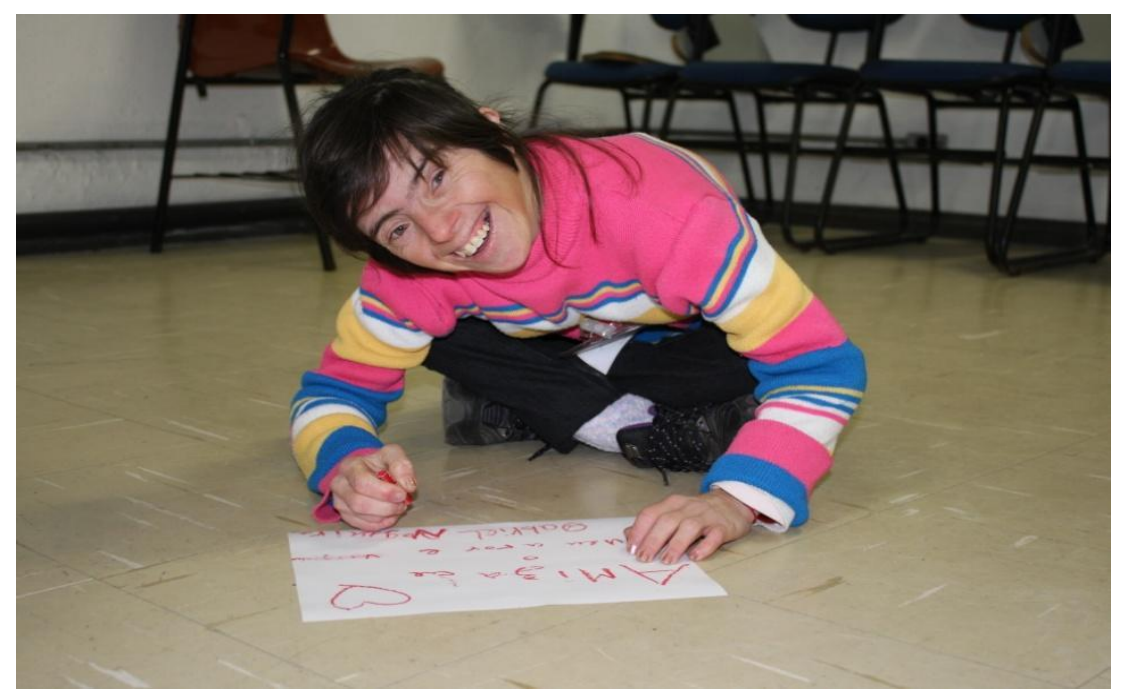

Figura 1- Participante no momento de reflexão e registro da oficina

Fonte: Acervo do Nals.

“(...) Não é possível continuar a prostituir a idéia de teatro, que só é válido, se tiver uma ligação mágica, atroz, com a realidade e o perigo.” (ARTAUD.2006 p.101). É a partir da leitura do primeiro manifesto "O teatro da crueldade" que o trabalho proposto se impulsiona. Sabemos que o fazer teatral, bem como, a performance esteve sempre à margem daquilo que é reconhecido como arte, sempre ocupando uma posição de resistência que se contrapõe a um saber entendido como real e que tem esse título voltado para resultados e não para o processo. Ainda que, no espaço acadêmico, o reconhecimento de uma outra forma de fazer comece a ganhar espaço, encontra-se resistência a manifestação livre desta visão do processo tão arte quanto o resultado, ou reconhecer que fragmentos do processo assim como a performance vezes são mais significativos ao artista que o resultado em si, esta inacabado, esta vivo, a performance deve ser reconhecidas como uma das artes que compõe esta arte plural que é teatro, juntamente com outras artes que se correlacionam dando vida a cena.

Partindo desses pressupostos, o Núcleo de Arte, Linguagem e Subjetividade (NALS) ${ }^{1}$,

\footnotetext{
${ }^{1}$ O NALS é um grupo que trabalha no ensino, pesquisa e extensão. Possui membros de vários cursos da universidade, entre eles: Teatro, letras, música, antropologia, engenharia, ciências sociais, filosofia, geografia, cinema, artes visuais. Além de alunos do mestrado e Doutorado em educação.
} 
vinculado a Faculdade de Educação (FAE) da Universidade Federal de Pelotas (UFPel), inicia há 5 anos sua trajetória com as Fronteiras da cidade de Pelotas, que desenvolve um "conjunto de projetos de valorização e visibilização de diversas formas de manifestações populares"(PINHEIRO, 2011, p. 81). Pensando em abrir o espaço acadêmico na perspectiva de experimentar novas possibilidades e vivenciar novas histórias, no ano de 2013 participantes do NALS propuseram a criação de oficinas de teatro, potencializando o encontro entre as artes. Teatro Down encontrou na vivência, um meio de fruição e reflexão da arte, especificamente o teatro a literatura a performance e a música, como uma outra-mesmahistória inseridas numa forma de fazer extra cotidiano onde o portador da síndrome de Down aplica os conhecimento adquiridos no processo de formação docente, somamos a idéia das oficinas a proposta do Colega Gabriel de estender este contive a outros grupos ao qual ele já participava.

O projeto se concretizou na parceria entre Nals e o grupo Novos Caminhos ${ }^{2}$, buscando constituir um espaço onde se concatene diferentes realidades na busca de uma práxis coesa, calcada na situação, especificamente, na vivência dos participantes e os movimentos sociais nos quais estão inseridos, corroborando com a fala de Pinheiro

\begin{abstract}
Sim, uma práxis, pois há o entendimento de que só o discurso é insuficiente para a mudança [...] Mais do que isso, compreende-se que um projeto coerente de transformação da sociedade vai além das novas esferas públicas: "No final, reformas mais amplas exigem não apenas que os professores se engajem em novos movimentos sociais, mas que [...] redefinam a natureza [...]. (PINHEIRO, p. 51, 2013)
\end{abstract}

Ao longo do ano de 2013 executamos 13 oficinas de Teatro com o grupo, intitulamos as Oficina de Teatro Down:Rompendo Fronteiras, os encontros eram conduzidos pelo colega Gabriel que tem síndrome de Down auxiliado pelo Nals e pelos bolsistas que acompanham o grupo novos caminhos, as oficinas foram direcionadas para um grupo de pessoas com uma diversidade de outras fronteiras, tais oficinas se tornam espetáculos de manifestações artísticas que não se restringem a uma nuance ou outra das artes, mas sim se coloca a dialogar entre todas elas, a literatura, a música, a dança, o teatro, as artes visuais, todos se encontram no local onde as oficinas ocorrem. O grupo se propôs inicialmente por meio destas oficinas ter uma metodologia voltada a discutir a importância da locomoção motora e a tradição oral no âmbito social e acadêmico. Assim, o presente ensaio tem em vista

\footnotetext{
${ }^{2}$ O Grupo novos caminhos trabalha no ensino, pesquisa e extensão. Possui freqüentadores com síndromes da comunidade em geral que não participam da rede de ensino regular.
} 
a apresentação e registro dessas atividades e a reflexão destas ações.

\section{2-Teatro estimulo lúdico para locomoção}

Quando pensamos na Oficina de Teatro, pensamos também em consciência corporal. A consciência do seu corpo possibilita um melhoramento significativo na condição de vida do ser. Criar um espaço onde há arte, que torne possível mover-se por uma sensação, que te desloca pelo espaço a um outro lugar, que te desassossega, que é poetizado. Um ambiente de descontração onde possamos imergir e emergir através da arte teatral.

Este foi o foco principal nas oficinas, mover o corpo através do fazer artístico, com propostas de alongamento, aquecimento, relaxamento e jogos que faziam o corpo deslocar-se pelo local, utilizando da oratória, ou seja, narrativas pessoais para tais estímulos, isto trouxe limitações do corpo e sociais, que naturalmente afloraram durante o processo e foram estimuladas com jogos e adaptações simples, para o melhor desempenho do grupo em geral que acompanhou o processo podendo absorver ainda mais do que estávamos programados a proporcionar.

\section{3-O Encontro}

O encontro ocorria na sala 259 da FAE, iniciávamos com uma roda onde todos estavam de mãos dadas, um processo de construção coletiva para buscar o silencio e assim após a euforia inicial e quando encontrávamos o estado de iniciar dávamos um bom dia e começávamos com os alongamentos, uma serie que busca alongar e informar sobre o corpo potencializando a consciência corporal, ativando-os para as práticas propostas, os participantes imersos nesta fase do encontro, rompiam as tensões dando outra energia ao espaço, as conversas após o bom dia eram direcionadas e focadas ao coletivo, através de perguntas e respostas o grupo identificavam coletivamente as áreas no corpo que necessitava de atenção. As perguntas aproximaram ainda mais o grupo dando abertura a curiosidades que iam desde o cotidiano de cada participante ate a metodologia teatral, muitos relatos de experiências emergiram nestes momentos preenchendo e enriquecendo o processo, isto exigiu foco e atenção coletiva neste estado onde o corpo que meche traz a tona questionamentos necessários a alma. Permitindo maior contato com os saberem contidos nas manifestações desta parcela da população da fronteira que vive a margem, poucas vezes reconhecidos como possíveis construtores de saber artístico/conhecimento cientifico. 


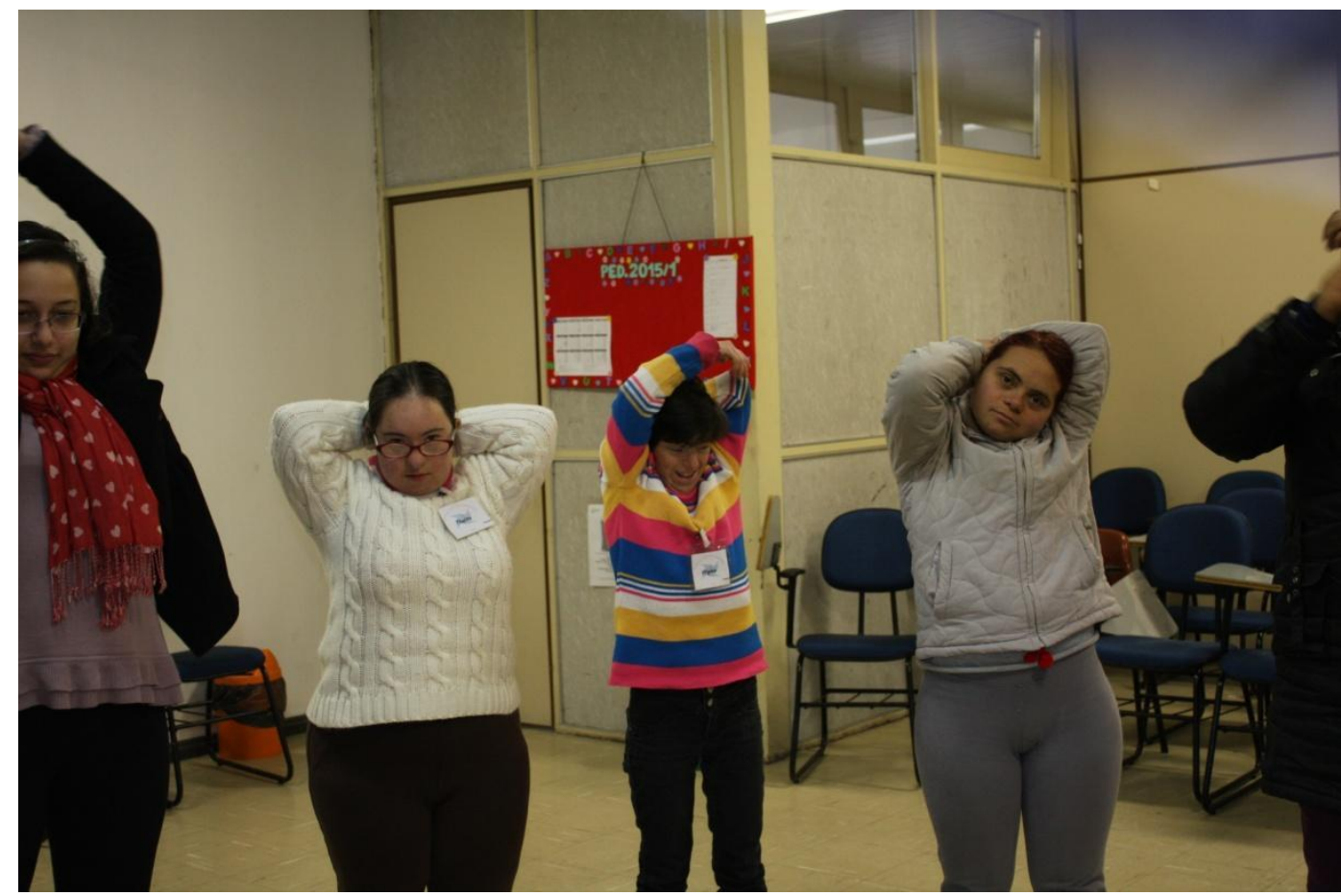

Figura 2- Grupo executando alongamento

Fonte: Acervo do Nals.

$\mathrm{Na}$ seqüência iniciávamos os aquecimentos com estímulos musicais onde era proposto experimentar outras formas de deslocamento e movimentação que viesse de uma relação com o sensível, sentir-se mover, mover e sentir, um saber individual conectado a narrativa destes contos feitos de forma oral retroalimentando o processo como estímulos para a movimentação. Ex: perguntávamos ao grupo como é o caminho da casa deles ate a Universidade, e dentro dos relatos encontrávamos situações e estímulos que resultava na experimentação de corpos neste outro espaço, ou como teríamos que andar dentro de uma caverna, e experienciavamos as respostas que vinham do corpo como abaixar o tronco ou rastejar pelo chão da caverna, ou como teríamos que andar se tivesse um cachorro vindo ao nosso encontro, essas narrativas eram feitas pelo próprio grupo, tendo de aceitar ou negar estímulos para poder compactuar com a proposta.

Com os corpos aquecidos passávamos para os jogos que eram jogos teatrais, com propostas diversas cada encontro executávamos 2 ou 3 jogos. (Ex: Siga o mestre, passa anel, níveis, espelho humano, estatua etc.) 


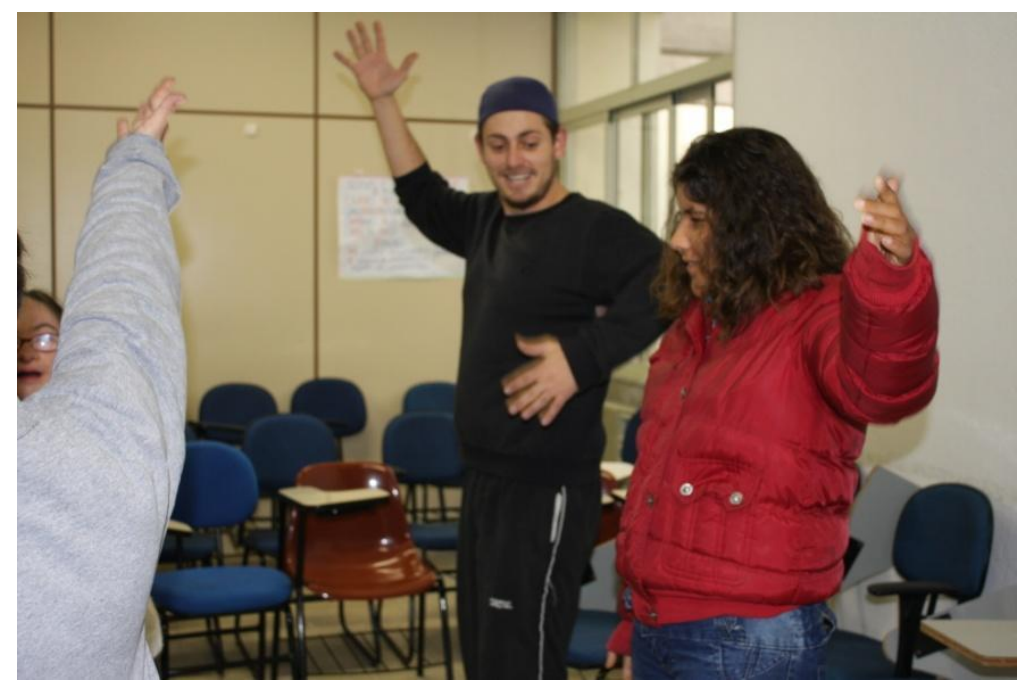

Figura 3- Jogo dos espelhos

Fonte: Acervo do Nals.

Os jogos tinham finalidades distintas como, por exemplo, o jogo do espelho que estimula não só a observação do corpo, como também a reflexão e a ação racional, projetando aquilo que é visto no corpo do colega com o próprio corpo, mover-se pela indução da leitura visual do outro. Estes jogos fizeram o grupo refletir muito em onde nossos corpos estão inseridos e como nos comportamos neste lugares, semelhanças nas reações a estímulos era perceptível, a doutrinação do corpo a sempre mover e sentir de formas programadas, portanto nos nossos encontros sair da rotina era uma constante, brincávamos ao aprender através do coletivo potencializando ao Maximo a experimentação do novo.

Dando seguimento iniciávamos uma fase de relaxamento e reflexão, com musicas pré-selecionadas, todos deitávamos ao chão, fechávamos os olhos para refletir o que tínhamos experienciado durante o encontro, quando a musica finalizava o grupo retornava a roda, agora sentados mais mantendo o circulo, no centro era disponibilizado diversos materiais, para que expressassem e registrassem sua reflexão acerca da experiência na forma que fosse escolhida, oralmente, desenhos, escrita, em forma da representação de uma cena, uma performance, estimulava-se que fosse um registro relacionado a experiência, uma maneira de potencializar o encontro ainda fazendo, o registro sublinha, uma outra ação relacionada a experiência vivida. Os encontros foram realizadas nas salas de aula da Faculdade de Educação-(FAE) da UFPel e tiveram a duração aproximadamente de uma hora cada encontro sendo ministradas nas quartas-feiras das 10 as 11 da manhã com orientação do Colega Gabriel Almeida Nogueira Licenciando em Teatro pela Universidade Federal de Pelotas e integrante do Nucleo de Artes, Linguagens e Subjetividade (NALS). 


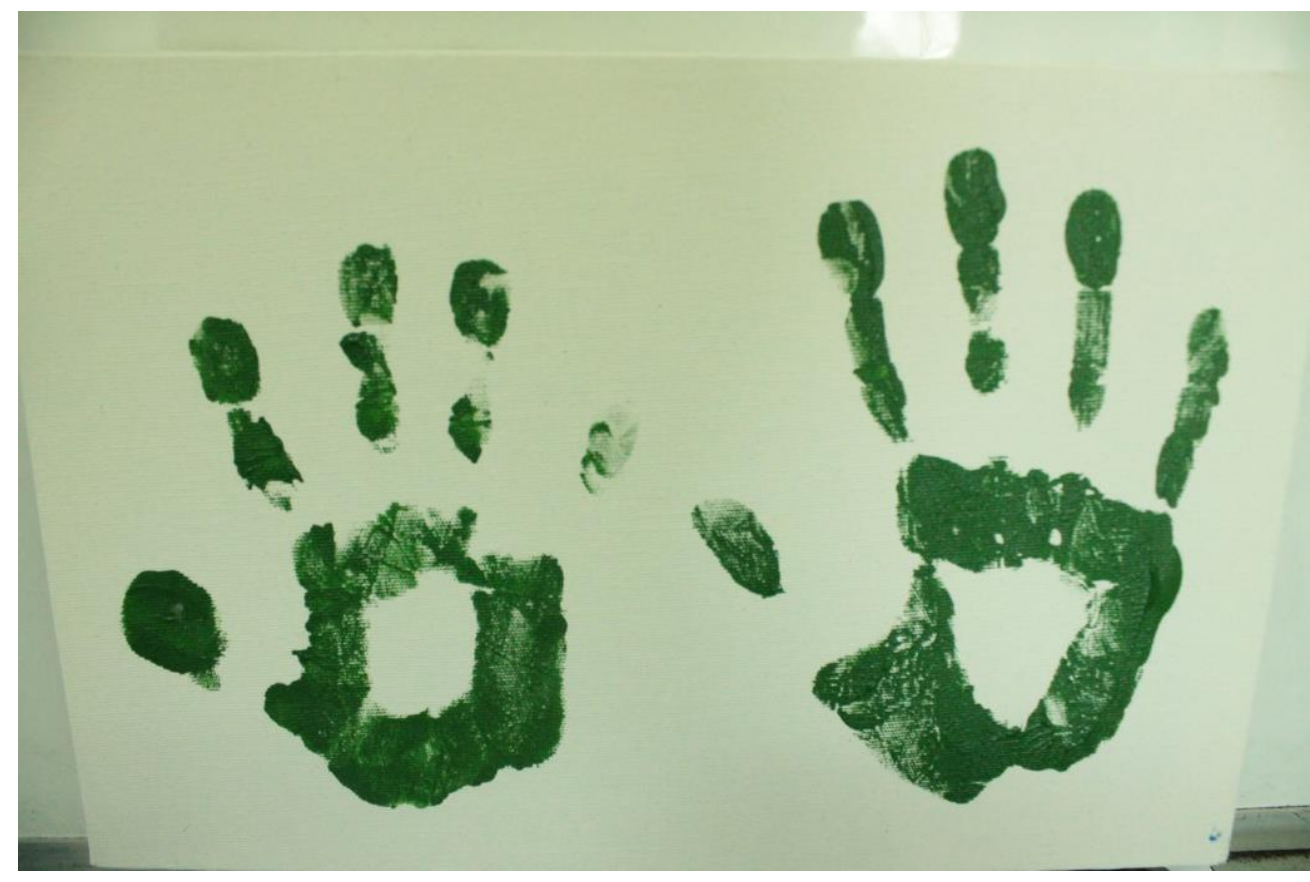

Figura 4- Registro feito por um dos participantes

Fonte: Acervo do Nals.

“A contação de histórias, a gesticulação, a mímica, o caminhar em cena, o agir e interagir com os ouvintes - a ação. (...) O aprendido continua sendo transmitido." (PINHEIRO, 2012). Ao final da oficina os participantes teciam comentários pertinentes ao trabalho, e estes comentários e os materiais de registro somados aos relatos dos participantes integrantes eram compartilhados com os outros integrantes do núcleo nas reuniões semanais do Nals, servindo de estímulos na estruturação do próximo encontro do Teatro Down, a poesia que encontramos nessa ação está relacionada a memória de uma história que agora não é de outro e dela também. Galeano (1995) na narrativa “A Casa das Palavras":

As palavras, guardadas em velhos frascos de cristal, esperavam pelos poetas e se ofereciam, loucas de vontade de ser escolhidas: elas rogavam aos poetas que as olhassem, as cheirassem, as tocassem, as provassem. Os poetas abriam os frascos, provavam palavras com o dedo e então lambiam os lábios ou fechavam a cara. Os poetas andavam em busca de palavras que não conheciam, e também buscavam palavras que conheciam e tinham perdido. (GALEANO, 1995, p.19)

Essas palavras ficam guardadas em registros que vão alem de textos e gravações, ficam dentro dos poetas, não precisam se oferecer para os eles, pois fazem parte deles, são levadas para todos os lugares. As palavras estão disponíveis para construir outras novasvelhas-histórias. 


\section{4-A Oficina e a performance}

“Suprimimos o palco e a sala, substituídos por uma espécie de lugar único, sem divisões nem barreira de qualquer tipo e que se tornará o próprio teatro da ação.” (ARTAUD.2006 p.110). Diante do toque das palavras Artaud sob uma necessidade de uma nova concepção do fazer teatral que não se rende a espaços físicos, estimulados por romper as paredes que materializam esta fronteira entre as ações do grupo e o mundo externo, no ultimo encontro sentimos a necessidade coletiva de vivenciar na rua esta experiência e utilizar deste local tão significativo para a arte teatral uma forma de sentir e fazer sentir, através da ação. Um piquenique com os participantes foi a proposta e assim deslocar a nós e a nossa arte de uma forma performática pela cidade de Satolep ${ }^{3}$, Teatro é Vida foi para a rua.

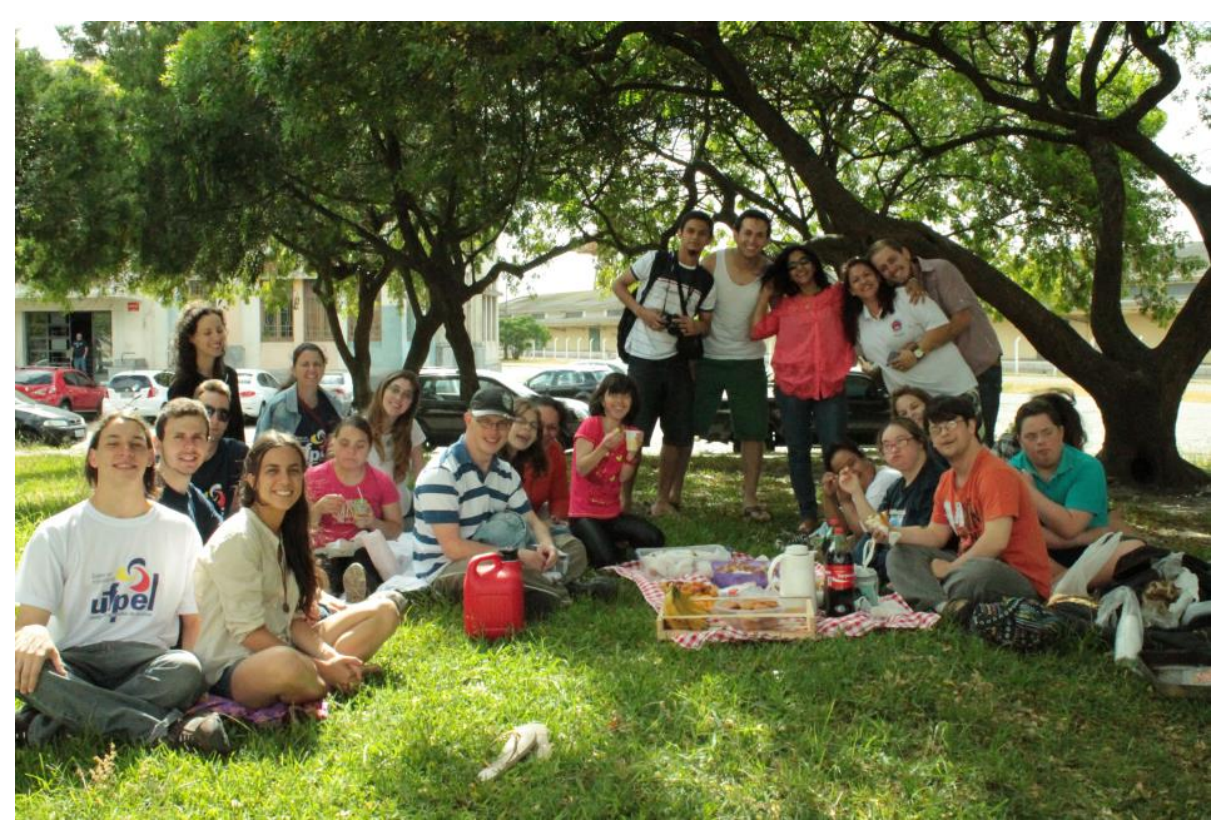

Figura 5- O grupo mais convidados durante o piquenique performático

Fonte: Acervo do Nals.

A performace constitui-se de uma ação simples de caminhar nas ruas Álvaro chaves entre o campus do $\mathrm{ICH}^{4}$ ao C.A $\mathrm{A}^{5}$, seguindo a proposta das ações criadas nos jogos feitos durante os encontros, com novas formas de caminhar que era coletivizadas para todo o grupo que neste ultimo encontro teve a participação de outros convidados, a coordenadora do projeto novos caminhos e um grupo de pesquisadores que já possuíam algum contato com o

\footnotetext{
3 Termo criado pelo musico Vitor Ramil para referenciar poeticamente a cidade de Pelotas em seus trabalhos .

${ }^{4}$ Instituto de Ciências Humanas da UFPel.

5 Centro de Artes da UFPel.
} 
projeto, que como no jogo do siga o mestre, trouxe a sensação de união, o andar em grupo e de forma extra-cotidiana gerou uma concentração de pessoas (publico) que pararam seus afazeres programados para verificar o que estava ocorrendo, uma ruptura no sistema que pausa e faz o homem refletir, o coro tão teatral estava na rua com corpos que se deslocavam carregados de energia e empoderamento.

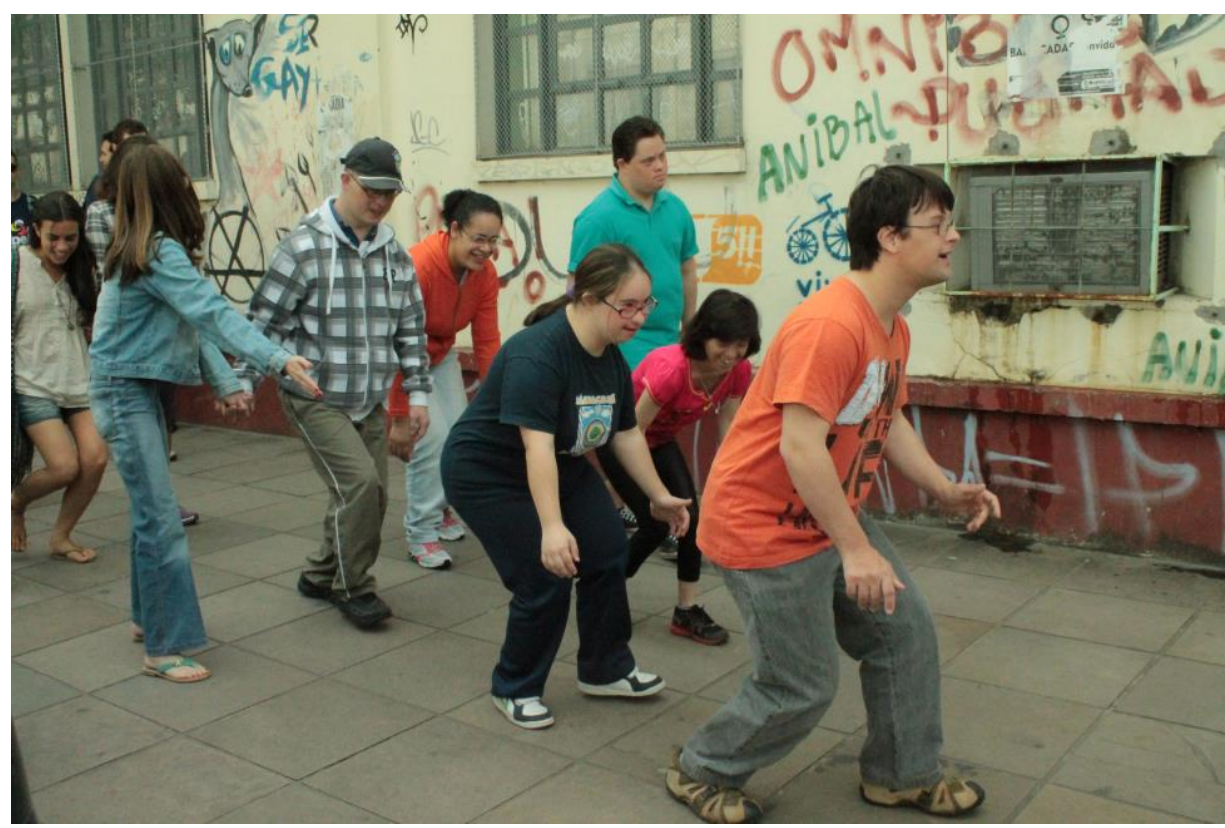

Figura 6-O grupo durante a performance.

Fonte: Acervo do Nals.

Em frente ao Centro de artes executamos a segunda parte da performance, foram distribuídos entre os participantes frases sobre o teatro a performance e uma relação entre os dois, com isso executamos uma nova ação, jogo do vivo morto foi feito e quando se dizia a palavra céu os corpos buscavam o céu e os participantes ficavam em pé mostrando as placas com as frases, quando falava-se a palavra terra os participantes agachavam em sentido ao chão e viravam as placas que continham as frases. Aqueles que não acertassem a ordem do levantar ou agachar céu/terra saída da performance o ultimo participante recebeu um cacho de banana, ele dividiu e todos comemos juntos as bananas em frente ao centro de artes com a intenção segundo ela de mostrar a todos que viram a performance que todos eram merecedores do premio assim como todos somos merecedores do acesso ao fazer teatral. 


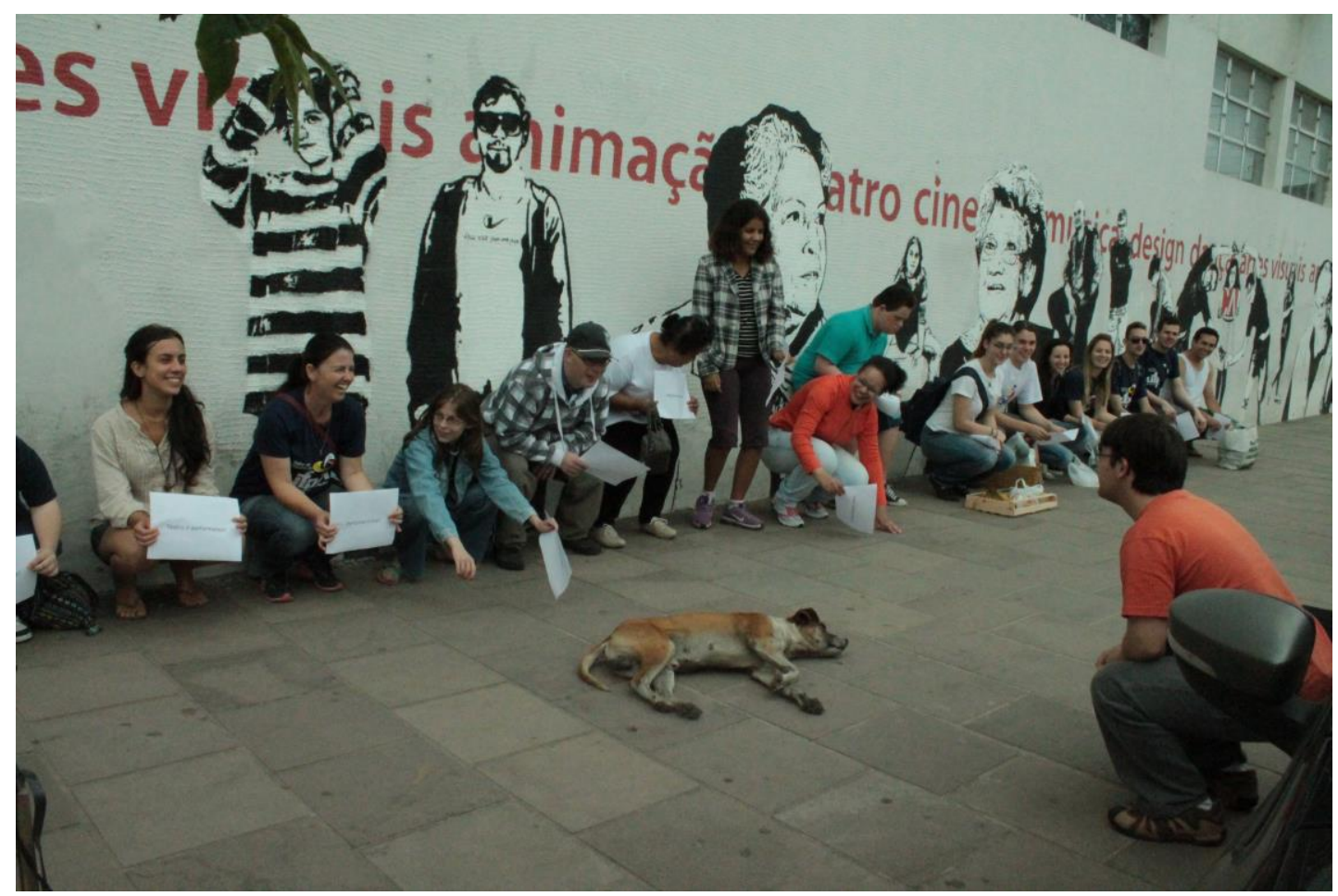

Figura 7-O grupo durante a performance.

Fonte: Acervo do Nals.

Toda a metodologia das oficinas se coloca no caminho das ações que permeiam as manifestações das culturas populares, a qual o grupo se reconhece pertencente. Os processos de ensino aprendizagem no contexto destas manifestações nem sempre ocorrem em espaços formais, e mesmo quando ocorrem nestes espaços, pela ação que desenvolvem se colocam dentro de outra perspectiva, compreendemos assim as ações das Oficinas de teatro Down, no que tange a performance como uma prática do ensino não-formal, de acordo com Gonh (2006),

A educação não-formal tem outros atributos: ela não é, organizada por séries/ idade/conteúdos; atua sobre aspectos subjetivos do grupo; trabalha e forma a cultura política de um grupo. Desenvolve laços de pertencimento. Ajuda na construção da identidade coletiva do grupo [...] fundamenta-se no critério da solidariedade e identificação de interesses comuns e é parte do processo de construção da cidadania coletiva e pública do grupo. (Gonh, p.30, 2006)

A oficina performance foi dividida em momentos, e em todos eles a consciência corporal se faz presente, e como já externado antes, a oficina se constitui de uma parceria entre grupo novos caminho e integrantes do NALS, do PET, e do Fronteiras, destaco então, que mesmo não vivenciando as mesmas manifestações das culturas populares que o grupo, existe uma congruência entre as vivencias dos integrantes que pertencem ao contexto da consciência corporal experenciada no Teatro Down e auxiliam no planejamento e execução da 
vida.

Claro que existem diferenças nas compreensões das propostas que se apresentam nas oficinas, principalmente quando adentramos os espaços da universidade, as culturas populares, e concomitantemente as ações do grupo, que são permeadas com um discurso de resistência, de subversão e até de liberdade, em contrapartida dos métodos tradicionais que encontramos nestes espaços, assim gerando aos participantes, um desassossego quanto à maneira que eles constroem seus saberes.

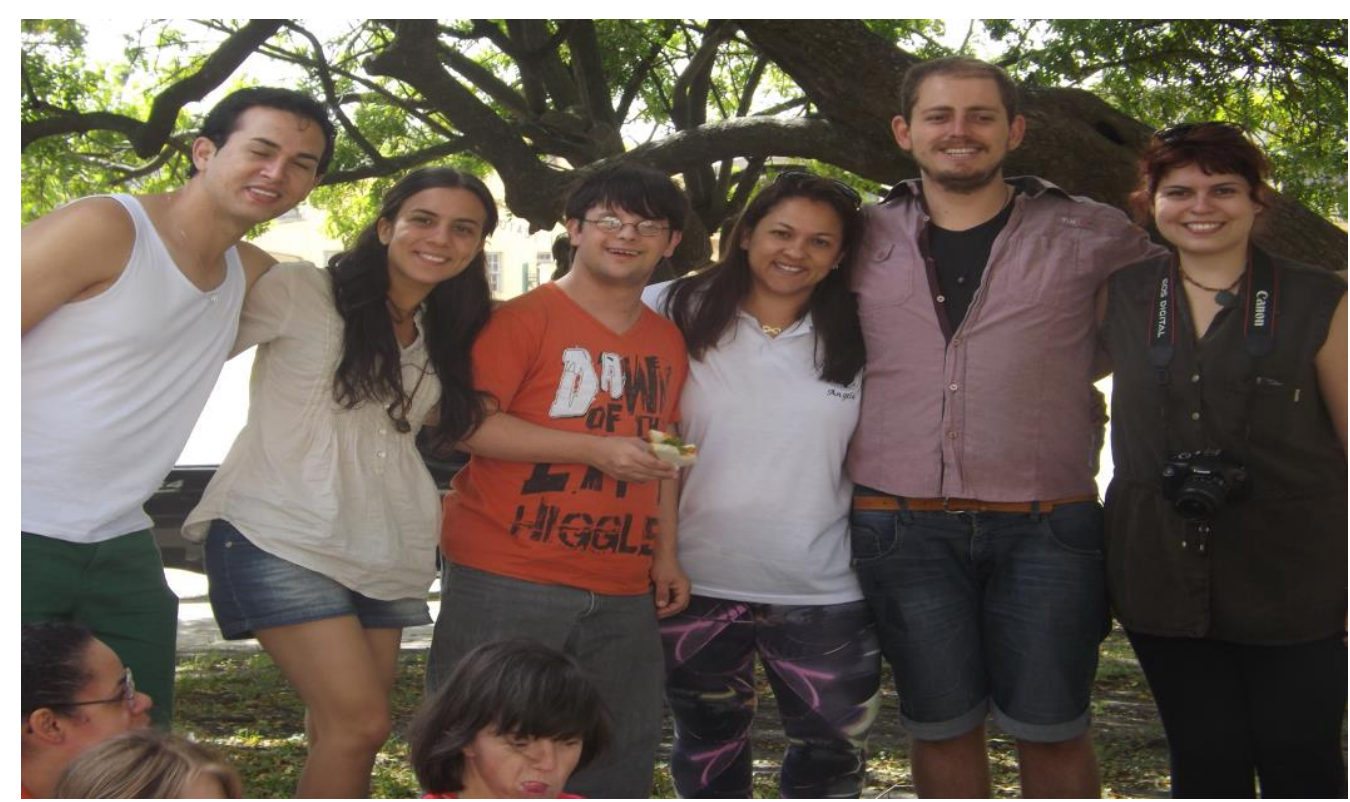

Figura 8-Equipe idealizadora do projeto

Fonte: Acervo do Nals.

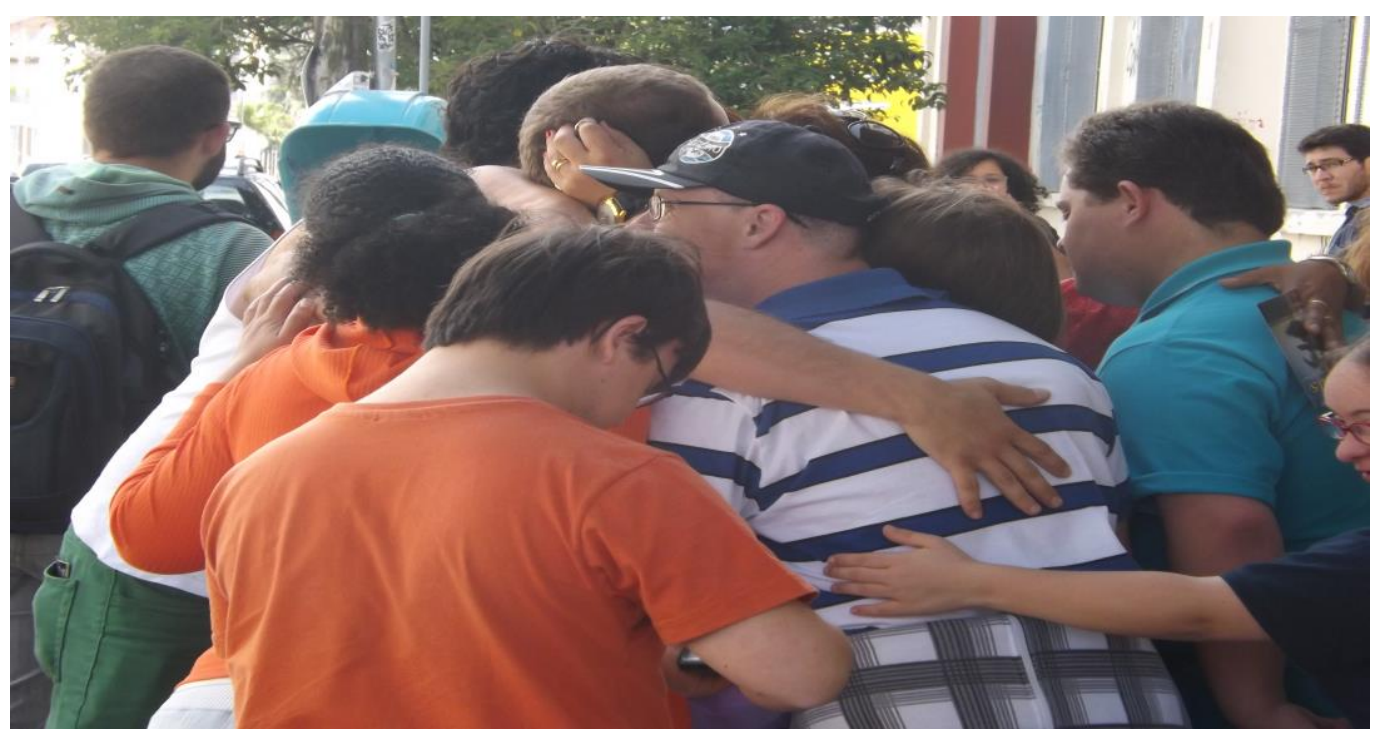

Figura 9-Grupo Teatro Down em abraço coletivo no encerramento do projeto 2013

Fonte: Acervo do Nals. 


\section{5-Considerações Finais}

A partir do discutido acima, acreditamos que estar no caminho certo, agindo para expandir o espaço de experimentação. Sabemos agora que a performance tem papel importante para a formação dos indivíduos, pois o empodera através de uma ação permeada não só pelo sugestionado pela sociedade mais recheado de reflexões e escolhas do próprio individuo, de modo a reconhecer a necessidade das artes e do fazer artístico no processo de estruturação do eu. Para além, o processo de educação trançado a cultura popular e os saberes populares nos permite perceber um outro-lugar real, mais vívido e sensível que quando tocado empodera e preenche a ação performática, cria uma mensagem e uma linguagem de expressão. Nos colocando em frente a realidade e nos expondo ao perigo do fazer um meio caminho entre o pensamento e o gesto. Performar com o grupo trouxe esta reflexão e constatação da importância da performance, colocou todos a frente de um publico que os analisava, que criava sentido para aquelas ações, um risco, e que refletia o seu estado de observador de uma ação extra cotidiana, alcançamos os objetivos com o grupo de acessar o fazer artísticos com metodologias e estímulos para a consciência corporal e social, dando espaço para outras formas de saber contribuindo de forma direta na vida dos participantes, e a experiência estética no cotidiano do púbico rompeu fronteiras. 


\section{6-Referências}

PINHEIRO, Cristiano Guedes; BUSSOLETTI, Denise Marcos. Educação e resistência na prática das narrativas populares: a tradição griô. In: IX Seminário ANPED SUL, 2012, Caxias do Sul. Anais do IX Seminário ANPED SUL. Caxias do Sul: Editora da Universidade de Caxias do Sul - EDUCS, 2012. v. CD-ROM. p. 1-15.

PINHEIRO, Cristiano Guedes ; BUSSOLETTI, Denise Marcos ; COSTA, Cleber. Programa Fronteiras da Diversidade: universidade e comunidade na construção de práticas sociais e culturais para a diversidade. Expressa Extensão (UFPel), v. II Dez, p. 79-102, 2011.

PINHEIRO, Cristiano Guedes, Narrativas de educação e resistência: a prática popular griô deDona Sirley; orientadora: Denise MarcosBussoletti; co-orientador: Jarbas Santos Vieira. - Dissertação (Mestrado em Educação) - Faculdade de Educação.Programa de PósGraduação em Educação. Universidade Federal de Pelotas, Pelotas, 2013.

DA GLÓRIA GOHN, Maria. Educação não-formal, participação da sociedade civil e estruturas colegiadas nas escolas. Rio de Janeiro: Revista Ensaio-Avaliação e Políticas Públicas em Educação, v. 14, n. 50, p. 11-25, 2006.

ARTAUD, Antonin. O Teatro e seu duplo. Traduzido por Teixeira Coelho. $3^{\mathrm{a}}$ Edição, Martins Fontes, São Paulo, 2006

GALEANO, Eduardo. O Livro dos Abraços. Porto Alegre: L\&PM, 1995. 